\title{
Greenness, civil environment, and pregnancy outcomes: perspectives with a systematic review and meta-analysis
}

Kyung Ju Lee ${ }^{1,2,3^{* \dagger}} \mathbb{D}$, Hyemi Moon ${ }^{4 \dagger}$, Hyo Ri Yun ${ }^{4}$, Eun Lyeong Park ${ }^{4}$, Ae Ran Park ${ }^{4}$, Hijeong Choi ${ }^{5}$, Kwan Hong ${ }^{2,3}$ and Juneyoung Lee Le $^{4^{*}}$

\begin{abstract}
Background: Various maternal conditions, especially in utero conditions and prenatal exposure to environments with air pollution and greenness, have been reviewed to address the enhancement and prevention of susceptibility to health risks, including low birthweight, preterm delivery, and preeclampsia. This study aimed to qualitatively and quantitatively investigate the associations between pregnancy outcomes and the characteristics of surrounding living environment, including greenness, air pollution, and civilization.

Methods: A secondary search of the MEDLINE, EMBASE, Cochrane Library, K-eArticles, and CINAHL databases was conducted without language restrictions to identify the relevant publications from the time of inception of the databases to April 2019.

Results: A total of 89 studies were identified, and 10 were included in the quantitative synthesis. The greenness of the environment within 100-, 250- and 500-m buffers, after adjusting for the air quality and civilization factors, was weakly but positively associated with birthweight. The pooled regression slope was 0.00134 (95\% confidence interval $[\mathrm{Cl}], 0.000,0.0020)$. The greenness of the environment was also associated with a significant decrease in the incidence of poor pregnancy outcomes, namely, low birthweight, small for gestational age (odds ratio [OR] 0.94; $95 \% \mathrm{Cl}, 0.92,0.97)$, and preterm delivery (OR 0.98; $95 \% \mathrm{Cl}, 0.97,0.99)$.

Conclusions: The greenness of the environment had a positive effect on the pregnancy outcomes, despite poor air quality and civilization. Following urbanization, planning for greenness management, environmental medicine, and public health is important and thus should be proposed as preventive methods as way of increasing birthweight and life expectancy.
\end{abstract}

Keywords: Greenness, Green space, Air pollution, Civilization, Pregnancy outcomes

\footnotetext{
* Correspondence: drlkj52551@korea.ac.kr; jyleeuf@korea.ac.kr

${ }^{\dagger}$ Kyung Ju Lee and Hyemi Moon contributed equally to this paper as first authors.

${ }^{1}$ Department of Obstetrics and Gynecology, Korea University Medicine, 73, Goryeodae-ro, Seongbuk-gu, Seoul 02841, South Korea

${ }^{4}$ Department of Biostatistics, Korea University College of Medicine, 73,

Goryeodae-ro, Seongbuk-gu, Seoul, South Korea

Full list of author information is available at the end of the article
}

(c) The Author(s). 2020 Open Access This article is licensed under a Creative Commons Attribution 4.0 International License, which permits use, sharing, adaptation, distribution and reproduction in any medium or format, as long as you give appropriate credit to the original author(s) and the source, provide a link to the Creative Commons licence, and indicate if changes were made. The images or other third party material in this article are included in the article's Creative Commons licence, unless indicated otherwise in a credit line to the material. If material is not included in the article's Creative Commons licence and your intended use is not permitted by statutory regulation or exceeds the permitted use, you will need to obtain permission directly from the copyright holder. To view a copy of this licence, visit http://creativecommons.org/licenses/by/4.0/ The Creative Commons Public Domain Dedication waiver (http://creativecommons.org/publicdomain/zero/1.0/) applies to the data made available in this article, unless otherwise stated in a credit line to the data. 


\section{Background}

Recently, the association between environmental factors and birth outcomes have been reviewed to address the effect the environmental factors before, during, and after pregnancy $[1,2]$. The fraction of the global burden of disease due to the environment is estimated to be up to $22 \%$ [3] and the urbanization of the environment associated with air pollution is also gradually increasing worldwide [4]. Although not fully understood, greenness in the urban environment is drawing attention as a potential health benefit for everyday life including mental and physical activities [2, 5-7]. In general, greenness is considered to reduce exposure to heat, noise, and air pollution and has a therapeutic effect on mental health $[6,8]$. Greenness is believed to primarily strengthen mental and physical activity, reduce mental and physiological stress, and support the public health community [8-10].

The Barker hypothesis, proposed in 1990, states that early intervention during pregnancy improves the health of newborns, which is greatly affected by various maternal conditions, including but not limited to nutrition, obesity, and gestational diabetes mellitus [11]. Exposure of pregnant women to ambient air pollution and to gradually increasing urbanization has been associated with adverse pregnancy outcomes such as low birthweight (LBW), preterm birth, intrauterine growth restriction, and congenital anomalies [12-15]. Pregnancy health outcomes associated with greenery were positively related to desirable pregnancy outcomes including increased birthweight and decreased preeclampsia and postpartum depression [16-20]. Herein, we aimed to investigate the associations between pregnancy outcomes and the characteristics of surrounding living environment, especially greenness, air quality, and civilization. Our research question was "What is the effect of greenness on maternal and neonatal health in the context of air pollution and related civilization?"

\section{Methods}

This systematic review and meta-analysis were performed in accordance with the Preferred Reporting Items for Systematic Review and Meta-analyses statement [21].

\section{Data sources}

The MEDLINE, PubMed, EMBASE, Cochrane Library, Korean Studies Information Service System (K-eArticles), and CINAHL databases were searched for reports published up to April 2019 without language restrictions.

\section{Search strategy}

A PubMed search for studies on green spaces, birth, or pregnancy outcomes was conducted without restrictions by combining search terms related to or synonymous with these terms. The keywords used in the PubMed search were "pregnant woman" or "pregnancy" for population; "green space," "park," "forest," or "greenness" for intervention; and "pregnancy outcome" or "birth outcome" for outcome. The terms were then converted to search tags that were used for the Cochrane Library and EMBASE database searches. For the "birth outcome," we included search terms suspected to be affected by the environment, such as "maternal illness," "birthweight," and "preterm birth" (Supplementary Table 1). Furthermore, the reference lists of the relevant articles were manually searched to identify additional studies.

\section{Study selection}

Greenness is an environmental characteristic, and access to green space is often not equitably distributed with respect to the socioeconomic backgrounds of the city residents. The normalized difference vegetation index (NDVI) is commonly used as an indicator of the presence and level of greenness. The NDVI was defined as the greenness measurement derived from the Landsat Enhanced Thematic Mapper Plus (ETM+) data at a resolution of 30 by $30 \mathrm{~m}$. Landscape databases such as Google Maps or the Greenspace Map in Scotland, which are adjusted for the effects of water-related variables, were excluded in this present study. The overall NDVI on the study-related population was also excluded. We selected buffer sizes of 100, 250, and $500 \mathrm{~m}$.

The exclusion criteria for the studies were as follows: absence of original data, such as that noted in review articles, editorials, commentaries, letters without new data analyses, meta-analyses, and abstracts only; greenness not presented as NDVI but as other parameters, such as percentage of green space in each urban or rural census area unit (CAU), tree-canopy cover, amount of total natural space; absence of the outcomes of interest in cases of gestational diabetes, gestational hypertension, preeclampsia; incorrect publication type; duplicated publication; and inconsistent variations in methodology.

\section{Data extraction}

The extracted information included the family name of the first author, year of publication, country of origin, number of study subjects, study duration, buffer size investigated, covariates used as cofounders for adjusting in a statistical model, outcomes assessed (birthweight, LBW, very LBW [VLBW], small for gestational age [SGA], preterm delivery [PTD], and/or very preterm delivery [VPTD]). In the present study, birthweight was defined as follows: The term birthweight was applicable to full-term births and was defined as term-appropriate birth weight of $>10 \%$ of the birthweight at $>37$ weeks of gestational age. Epidemiologically various estimated SGA 
based on the reference population SGA was defined as birthweight $<10 \%$ of that for a specific gestational age. Preterm birth was defined as birth before completion of 37 weeks of gestation. Low birthweight (LBW) and very LBW (VLBW) were defined as birthweight <2500 g and $<1500$ g, respectively.

The covariates were categorized into subject demographic variables; those related to air pollution such as $\mathrm{NO}_{\mathrm{x}}$ and/or particulate matter $(\mathrm{PM})_{\mathrm{x}}$; and factors regarding civil environments such as population density, noise, and/or distance to the nearest park.

Most studies employed a multivariable linear regression or nonlinear regression spline models to evaluate the effects of greenness on birthweight and multivariable logistic regression or generalized estimating equation models to examine its effect on the odds of (V) LBW, SGA, or (V)PTD. Therefore, as effect sizes, we used the reported regression coefficients and the adjusted odds ratios, along with their standard errors.

We investigated the greatest possible impact of greenness when we extracted the estimated adjustment effect with standard error or the corresponding 95\% confidence intervals (CIs). We selected a model that reflected the greatest potential confounders for the key analysis that was provided in the body of the article or the supplementary material. The characteristics of the studies are shown in Table 1 according to the NDVI buffer size, covariates, and pregnancy outcomes.

\section{Data and statistical analyses}

As the buffer sizes of the NDVI examined varied among the included studies, we selected buffer sizes of 100, 250, and $500 \mathrm{~m}$ for which at least two studies were available. The outcomes of our quantitative synthesis were summarized as (1) term birthweight, (2) low birthweightrelated outcomes (LBW, VLBW, or SGA), and (3) preterm birth (PTD or VPTD). The confounding factors for the effect of the NDVI on these outcomes were categorized as subject demographic characteristics, factors associated with air quality, and factors associated with civilization. The degree of civilization was mainly expressed by the population density and traffic density, town of residence, noise, or walkability.

The estimated regression coefficient and its standard error for the effect of greenery on the birthweight from the results of multivariable regression models were categorized according to the buffer size and types of confounders. In this review, owing to the different NDVI exposure units, a standardized regression coefficient for birthweight was used as an effect size index [30]. The standardized coefficient was calculated using the following formula: [(SD of NDVI)/(SD of birthweight $) \times$ unstandardized coefficient] [31]. When the SD of the NDVI was not reported, we imputed it using the following formula: (third quartile of the NDVI -first quartile of the NDVI)/1.349, if the interquartile ranges were provided for the NDVI or (maximum NDVI -minimum NDVI)/6, if the NDVI range was reported. A standardized odds ratio (OR) for the effects of greenness on pregnancy outcomes (low birthweight-related outcomes or preterm birth) was also calculated as follows: (natural logarithm of the reported OR divided by the reported NDVI exposure unit is multiplied by 0.1 and then exponentiated.

A meta-analysis was conducted using a random-effects model owing to the limited number of studies available along with the observed heterogeneity among the studies. The synthesized results were presented as standardized regression coefficients or standardized ORs, as appropriate, with corresponding 95\% CIs. The statistical heterogeneity between studies was assessed using the tau-squared values, Cochran's Q-tests, and Higgins' Isquared statistics. For the $\mathrm{Q}$ statistic, heterogeneity was considered to be present if the $P$-value was $<0.1$. We defined low, moderate, and high heterogeneity as $\mathrm{I}^{2}$ values of 25,50 , and $75 \%$, respectively.

Publication bias was evaluated by visual inspection of the contour-enhanced funnel plots [23, 32] and was tested using Egger's tests [33]; P-value of $<0.1$ was considered indicative of publication bias. No subgroup analysis was pre-defined and performed.

However, sensitivity analyses were conducted for the effect of greenness on the term birthweight by omitting the most influential study [34] and by restricting studies that adjusted for the $\mathrm{PM}_{\mathrm{x}}$ of the air quality and demographic characteristics of the subjects $[35,36]$ to test the robustness of the overall pooled results. In addition, random-effects meta-regression analysis was performed to examine the dose-response relationship between the effects of buffer size and NDVI on birthweight.

All statistical analyses were conducted using $\mathrm{R}$ version 3.6.0 (R Foundation for Statistical Computing, Vienna, Austria) and Review Manager version 5.3 (The Cochrane Collaboration, The Nordic Cochrane Centre, Copenhagen, Denmark). Stat $P$-values $<0.05$ were considered statistically significant, except for the results of the Cochran's Q-test and in the evaluation of publication bias.

\section{Quality assessment}

The Risk of Bias Assessment tool for Non-randomized Study (RoBANS) was used to assess the risk of bias in the included studies [37]. The RoBANS consists of six domains that include participant selection, confounding variables, intervention measurement, outcome assessment blinding, incomplete outcome data, and selective outcome reporting. The tool assessed the risk of bias for each domain as high, low, and uncertain. 


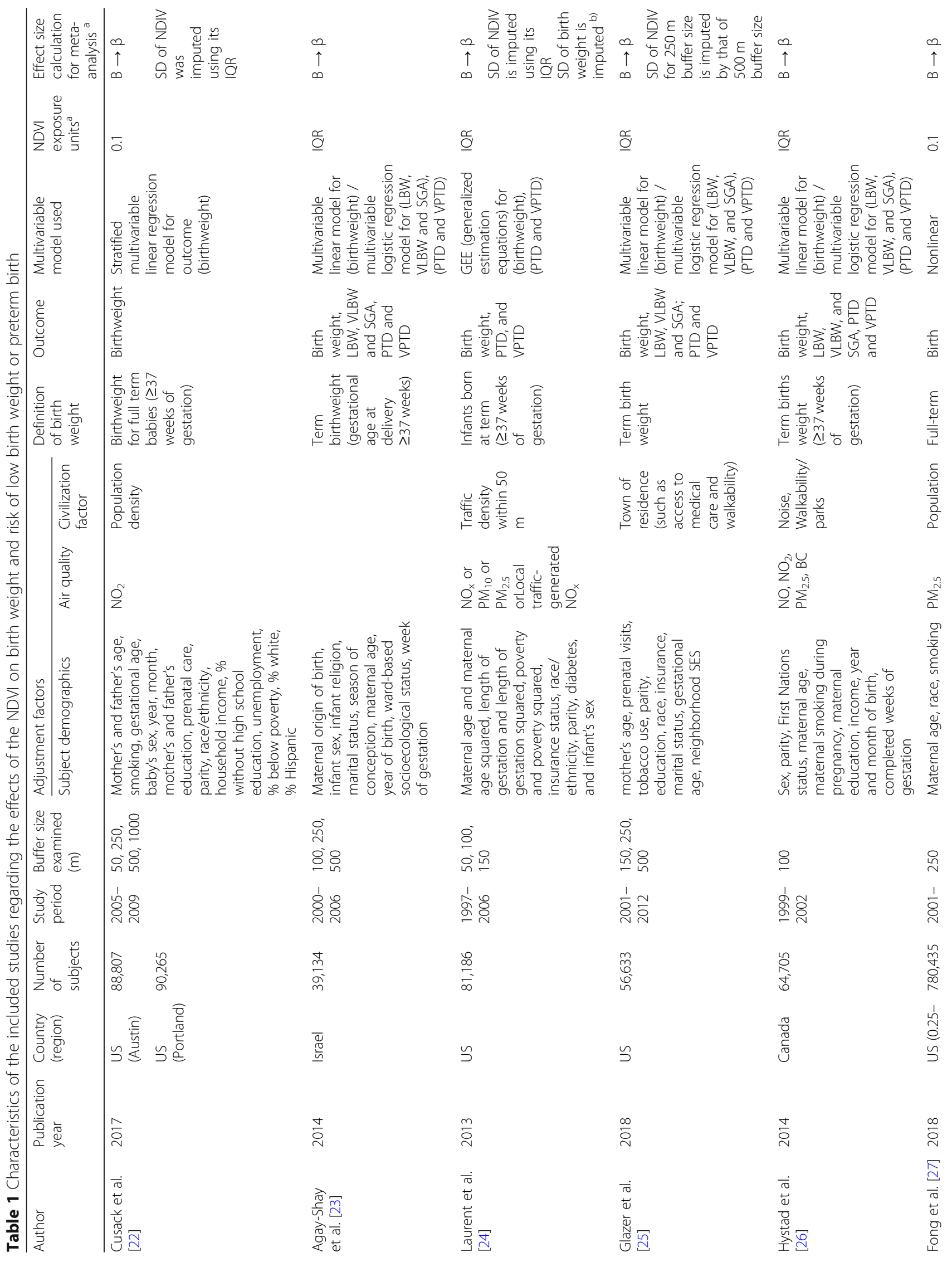




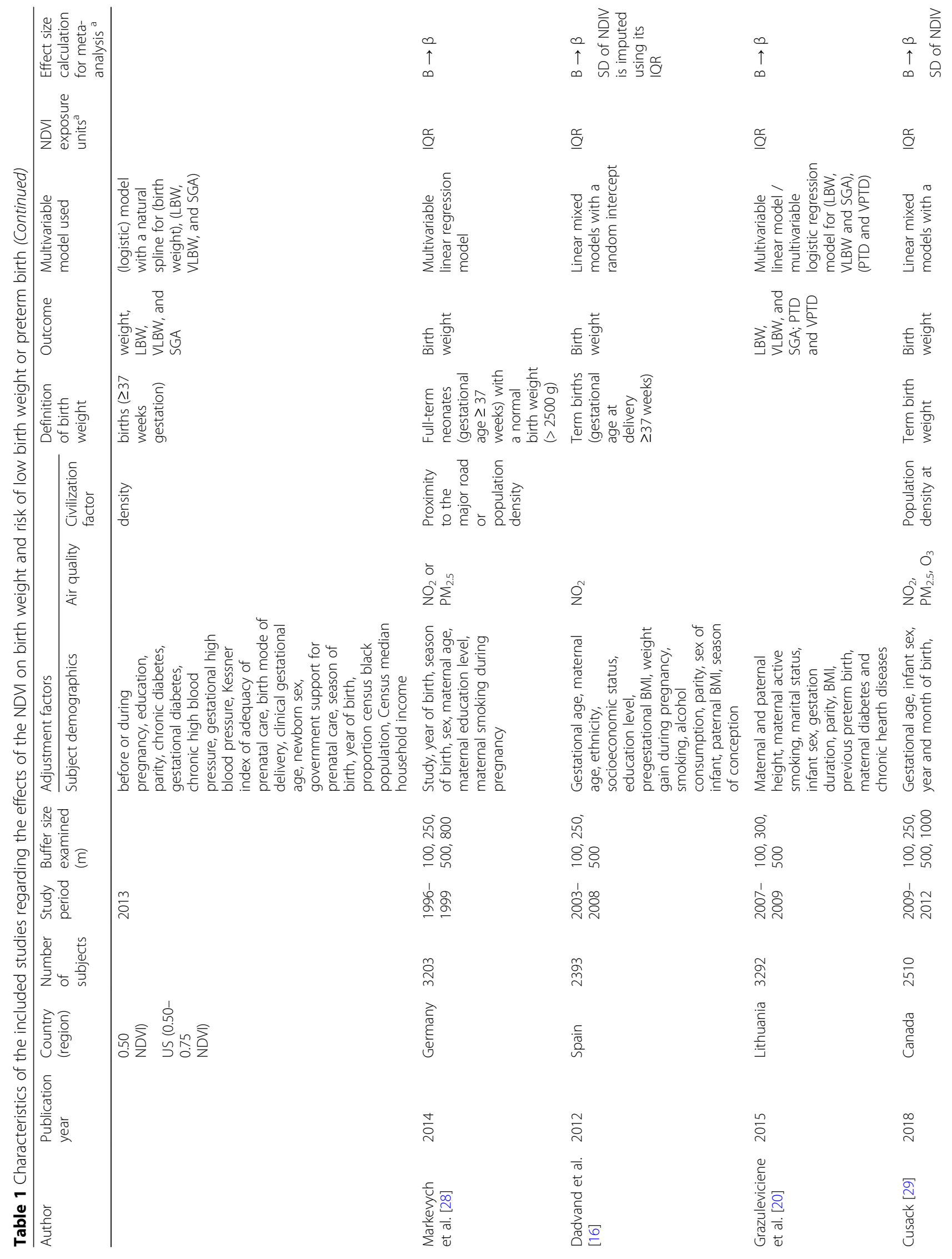




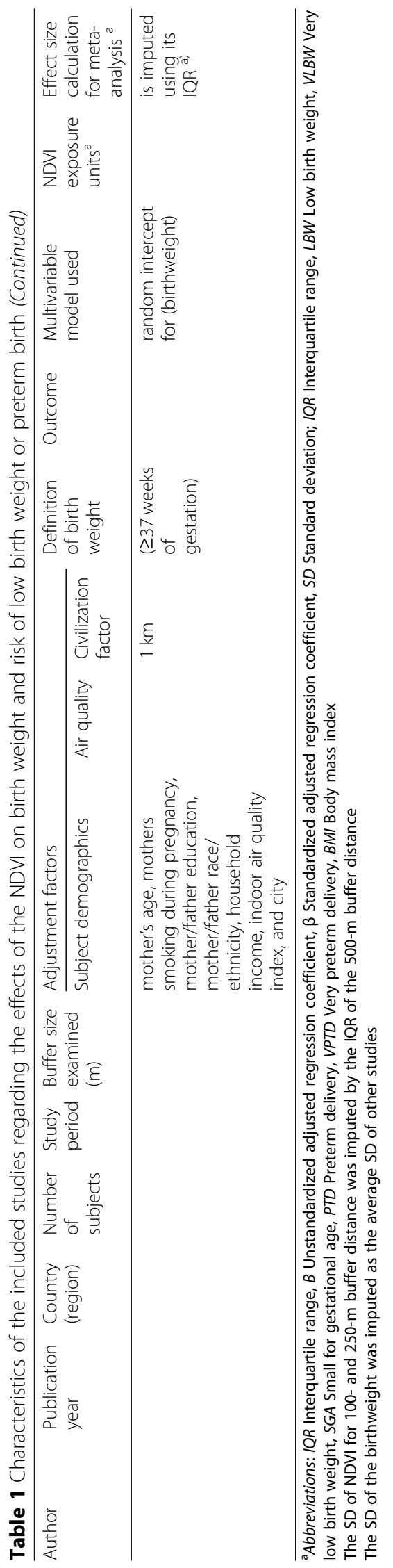




\section{Results}

The study selection process is detailed in Fig. 1. Briefly, after an initial screening of the titles and abstracts of 89 potentially relevant articles on the effect of the NDVI for greenness on birth or pregnancy outcomes, the full text of 33 studies was reviewed. After excluding 23 studies that did not meet the inclusion criteria, we identified 10 articles (9 articles for birthweight [20, 22, 24, 28, 34-36, $38,39]$; 5 articles for LBW [20, 22, 28, 29, 39]; and 5 articles for preterm birth [20, 22, 29, 35, 39]). The characteristics of the included studies are summarized in Table 1 and the risk of bias is shown in Fig. 2. All included studies were published in 2012 or later, had sample sizes ranging from 2393 to 780,435 participants, and study years ranging from 1996 to 2013. Our studies included a total of 1,212,563 subjects. All studies were performed in North America or Western Europe, except for one from Israel and one from Lithuania. The examined buffer sizes varied among studies, from 50 to $1000 \mathrm{~m}$ but most included 100, 250, and $500 \mathrm{~m}$. Analysis of air pollution also varied from $\mathrm{NO}, \mathrm{NO}_{2}$, and $\mathrm{O}_{3}$ to $\mathrm{PM}_{2.5}$ and $\mathrm{PM}_{10}$.

To assess the effect of greenness on term birthweight after adjusting for potential confounders, seven of the 10 studies included in the meta-analysis employed a multiple linear regression model, whereas three studies [27,
28 , 35] used a multiple linear regression model with a random intercept, a multiple linear mixed model with a random cohort effect, and a generalized estimating equation to evaluate within-hospital correlation, respectively.

The 10 studies evaluated the effects of greenness as follows: with adjustment for the subject demographic variables only [20, 22, 24, 34, 35, 39], with adjustment for demographic and air quality variables [22, 34-36], and with adjustment for demographic and civilization factors regardless of air quality management [22, 24, 28, 35, 36, 38, 39].

Figure 3 shows the results of the meta-analysis on the effects of greenness on birthweight stratified by the NDVI buffer size with standardized regression coefficients and adjusted for demographic variables. Although the heterogeneity among studies was considerable $\left(\mathrm{I}^{2}=\right.$ 91\%), the NDVI distance was significantly positively associated with birthweight gain [34]. Except for a very study reporting a high association (Dadvand, et al., 2012c) [16], the overall effect of greenness on birthweight remained significant. (pooled estimate, 0.0019; 95\% CI, 0.0009, 0.0028) (Supplementary Figure S1)

In two studies on the effects of greenness on birthweight stratified by the NDVI buffer sizes (250 and 500 $\mathrm{m})$, a meta-analysis was conducted by adjusting for other

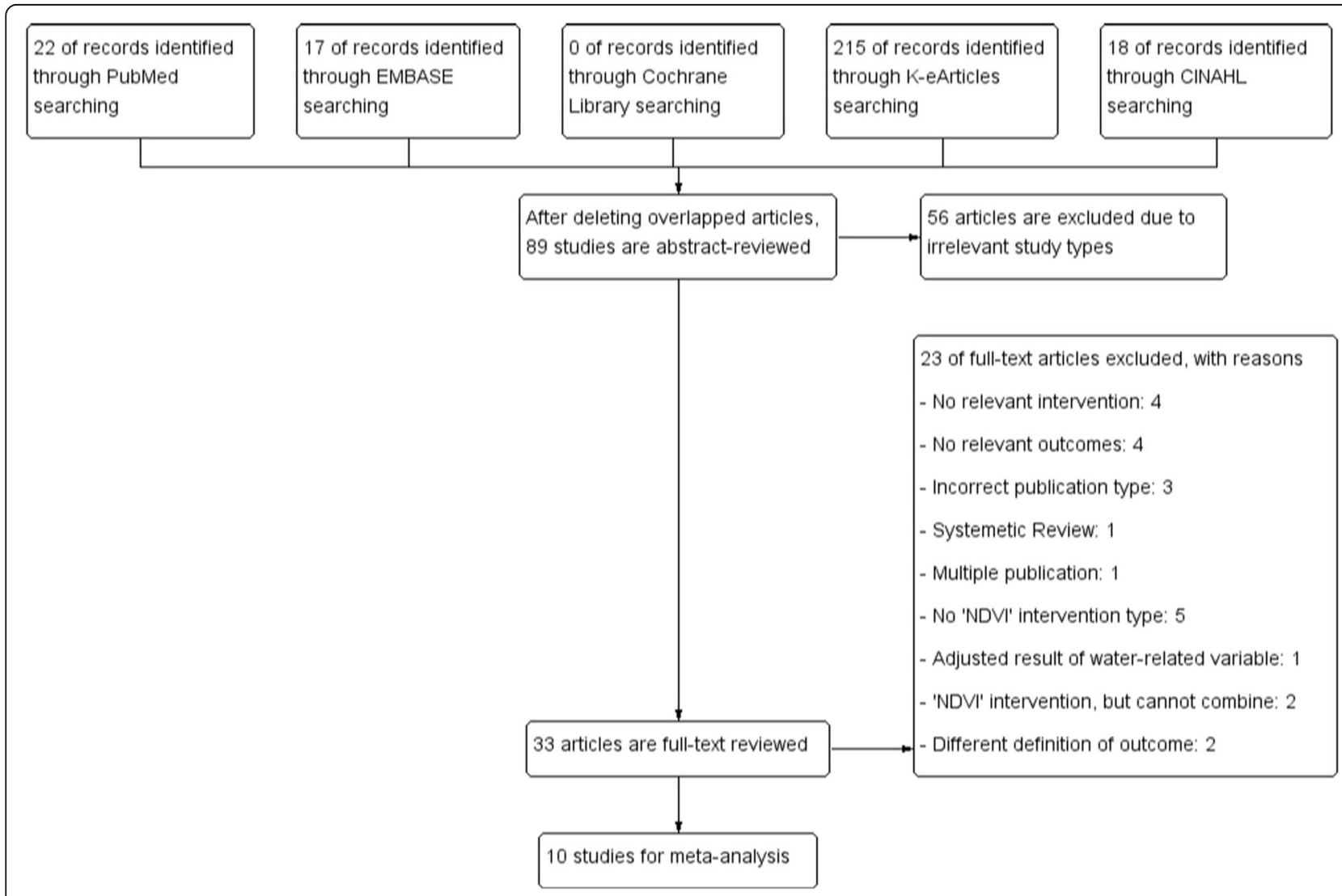

Fig. 1 Flow diagram of the search strategy and study selection 


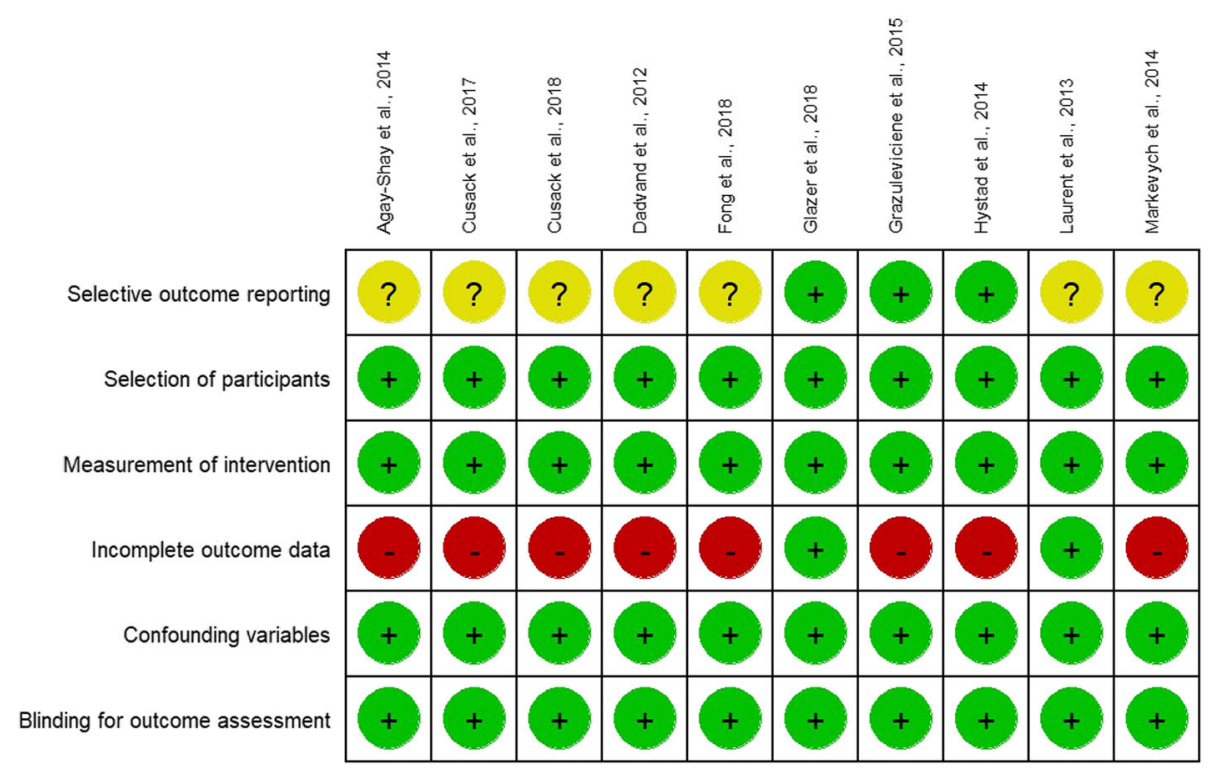

Fig. 2 Risk of bias summary. The authors' judgments regarding each risk of bias item for the included studies were determined using the Risk of Bias Assessment tool for Non-randomized Study

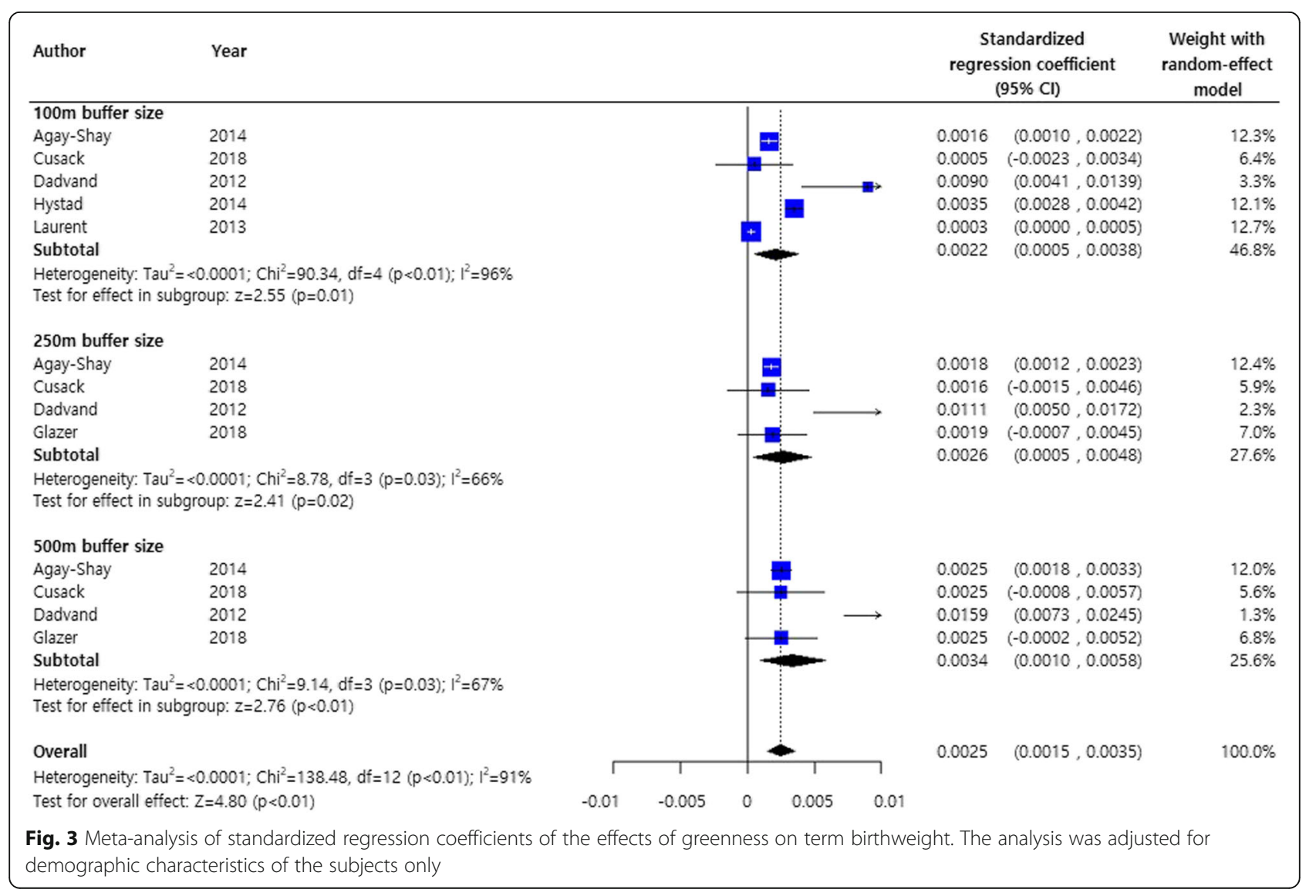


air quality factors including $\mathrm{PM}_{2.5}$ and $\mathrm{PM}_{10}[35,36]$. Even in the presence of air pollutants, greenery was associated with birthweight gain (pooled estimate, 0.0003; 95\% CI, 0.0002, 0.0005) (Supplementary Figure S2). After adjusting for civilization factors, regardless of air quality, the NDVI buffer distances produced different results for birthweight gain: high birthweight gains with a 100 -m buffer distance $(0.0026 \mathrm{~g}, 95 \% \mathrm{CI}, 0.0001,0.0050)$, medium birthweight gain with a 500-m buffer distance $(0.0015 \mathrm{~g}, 95 \% \mathrm{CI},-0.0010,0.0040)$, and LBW gain with a $250-\mathrm{m}$ buffer distance $(0.0009 \mathrm{~g}, 95 \% \mathrm{CI},-0.0003$, 0.0022) (Fig. 4).

Investigation of the effects of greenness on poor pregnancy outcomes showed a significant decrease of about $6 \%$ for LBW, VLBW, and SGA (pooled standardized odds ratio OR, 0.94; 95\% CI, 0.92, 0.97) [20, 22, 28, 29, 39] (Fig. 5).

However, the overall NDVI effect of reducing poor pregnancy outcomes should be interpreted with caution as the subgroup results for each buffer size $(100,250$, and $500 \mathrm{~m})$ did not reach statistical significance. Nevertheless, low occurrences of LBW, VLBW, and SGA were shown at all NDVI distances. No publication biases were observed in the study adjusted for demographic and civilization factors (Fig. 6a) and poor pregnancy outcomes (LBW, VLBW, and SGA) were not statistically significant (Supplementary Figure S3 B).
To evaluate publication bias, the contoured enhanced funnel plot for birthweight data was reviewed. Figure 7 shows no asymmetry within these plots, except for the middle panel. The middle panel funnel plot indicated some non-significant small effect-size studies lacking adjustment for demographic characteristics and air quality (Fig. 7b). There were small values for the inverse standard error of the regression coefficient for the NDVI effect, i.e., small sample sized studies found at the lower white space in the funnel plot. This possibility of publication bias partly explained the unexpectedly large NDVI effects associated with a buffer size of 250 and $500 \mathrm{~m}$ observed in Fig. 8.

A random-effects meta-regression was conducted to investigate changes in the standardized mean birthweight for different NDVI buffer sizes after adjusting for demographic and civilization factors but not air quality (Supplementary Figure S3A). As the buffer size increased, the variability of the standardized mean birthweight decreased (regardless of air quality), although the trend was not statistically significant $(\mathrm{P}$ for linear trend $=$ 0.5157).

The meta-analysis of the effect of greenery on preterm birth included only a 100-m NDVI buffer [22, 25, 29, 35, 39]. A statistically significant $2 \%$ average decrease in preterm birth was observed (pooled OR 0.98; 95\% CI, 0.97, 0.99) (Fig. 9) and no obvious publication bias was detected (Fig. 7b).

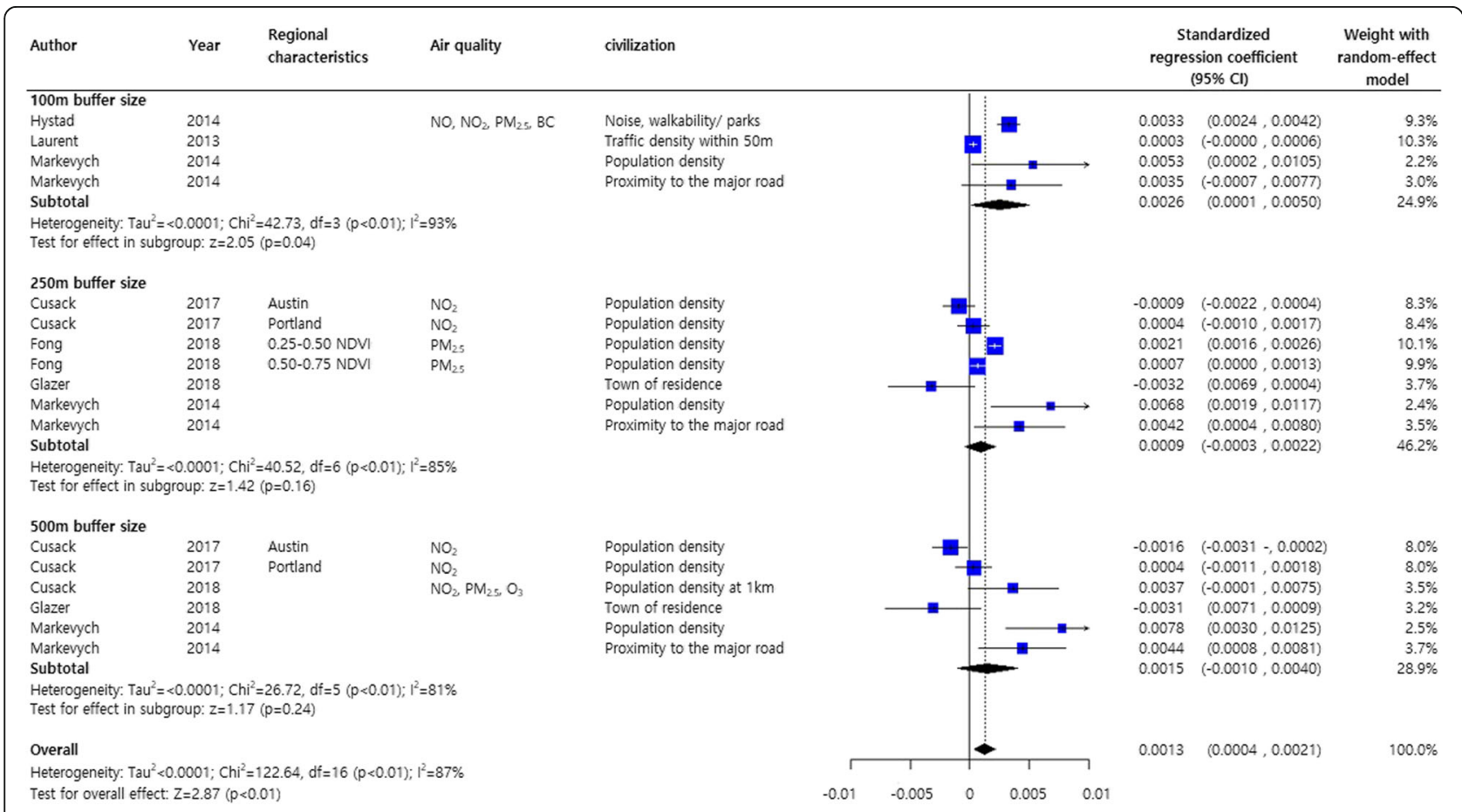

Fig. 4 Meta-analysis of standardized regression coefficients for the effects of greenness on birthweight. The analysis was adjusted for subject demographic characteristics and civilization factors regardless of air quality effects 


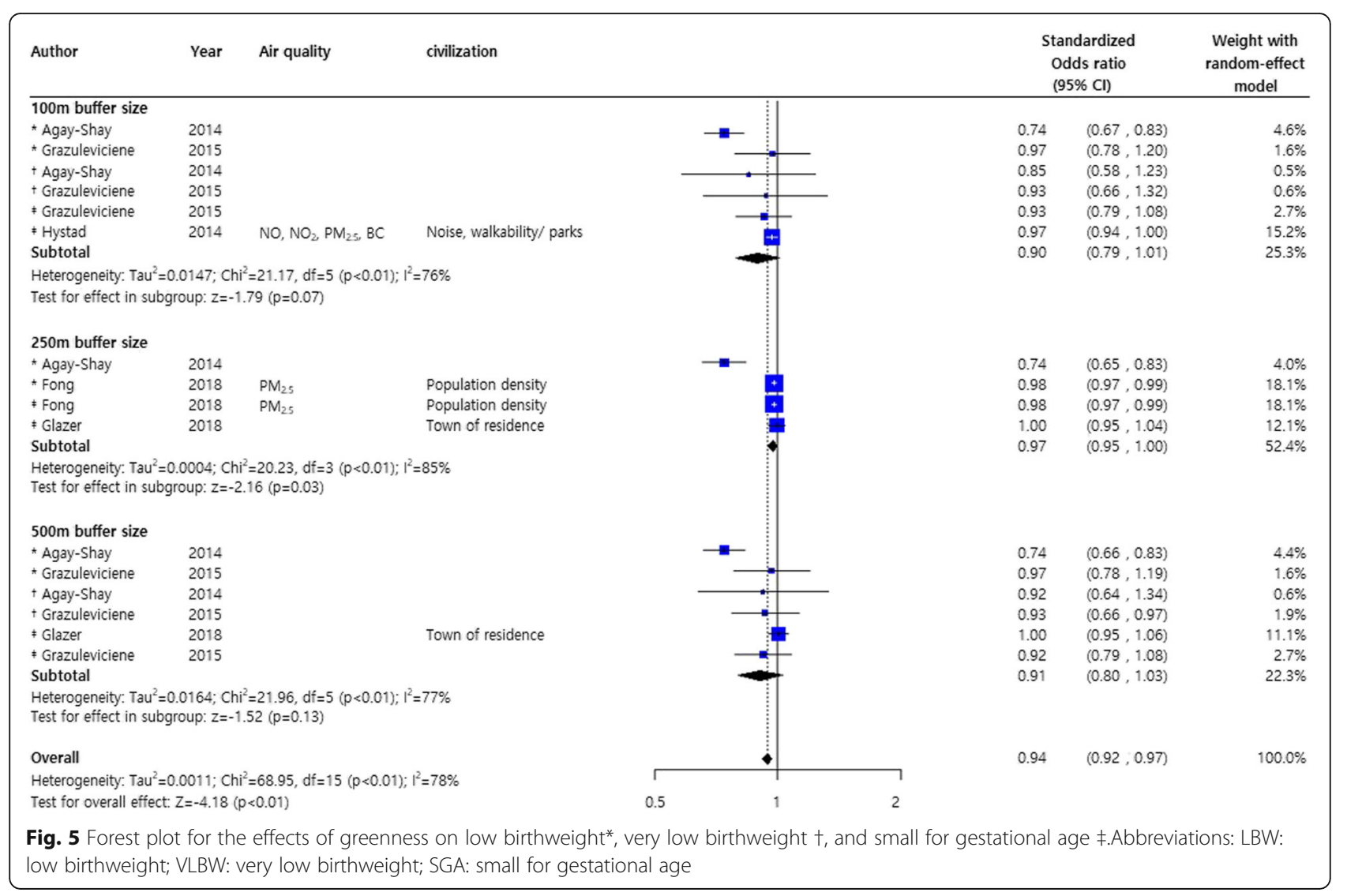

\section{Discussion}

We performed a meta-analysis to investigate the effect of green and civil environments on the pregnancy outcomes while considering the associated factors, such as ambient air pollution and civilization. To the best of our knowledge, this is the first study to extend the work to assess the effects of greenness in with the context of the proximity to air pollution sources on the pregnancy outcomes. This study was provided stratification of greenness and adjusted air quality for the investigation of poor pregnancy outcomes, such as LBW, SGA, and preterm birth, showing a weak positive effect and a
A

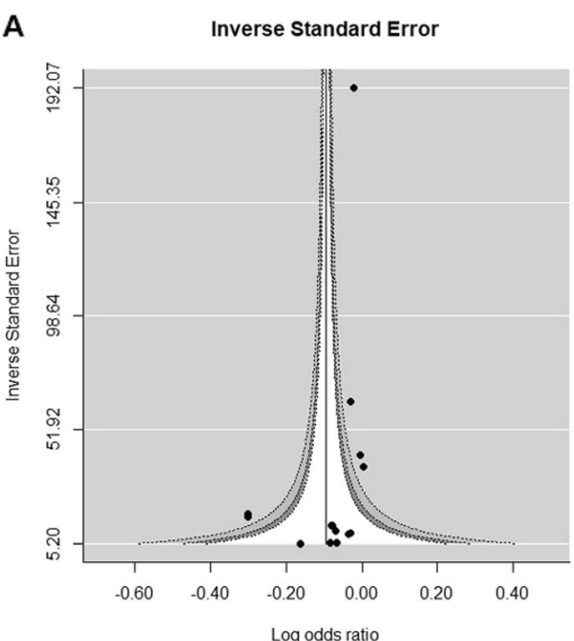

B

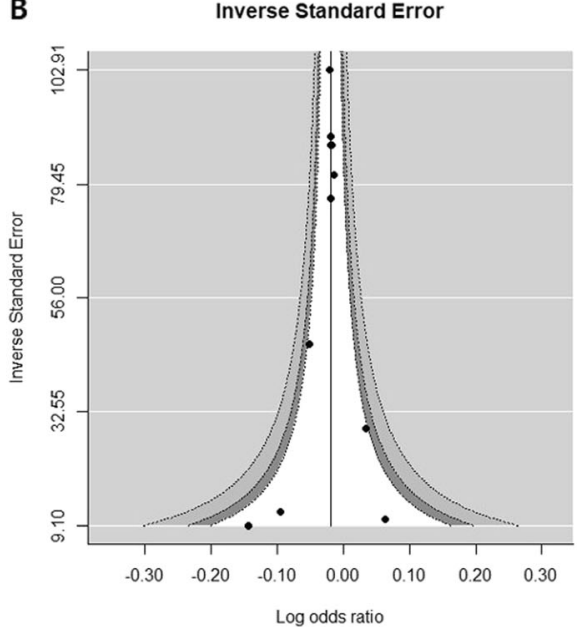

Fig. 6 Funnel plot. The plot shows low birthweight related pregnancy outcomes (LBW, VLBW, or SGA) (a, $P=0.3556$ for Egger's test) and preterm birth (PTD or VPTD) (b, $P=0.6952$ for Egger's test). Abbreviations: LBW: low birthweight; VLBW: very low birthweight; SGA: small for gestational age; PTD: preterm delivery; VPTD: very preterm delivery 

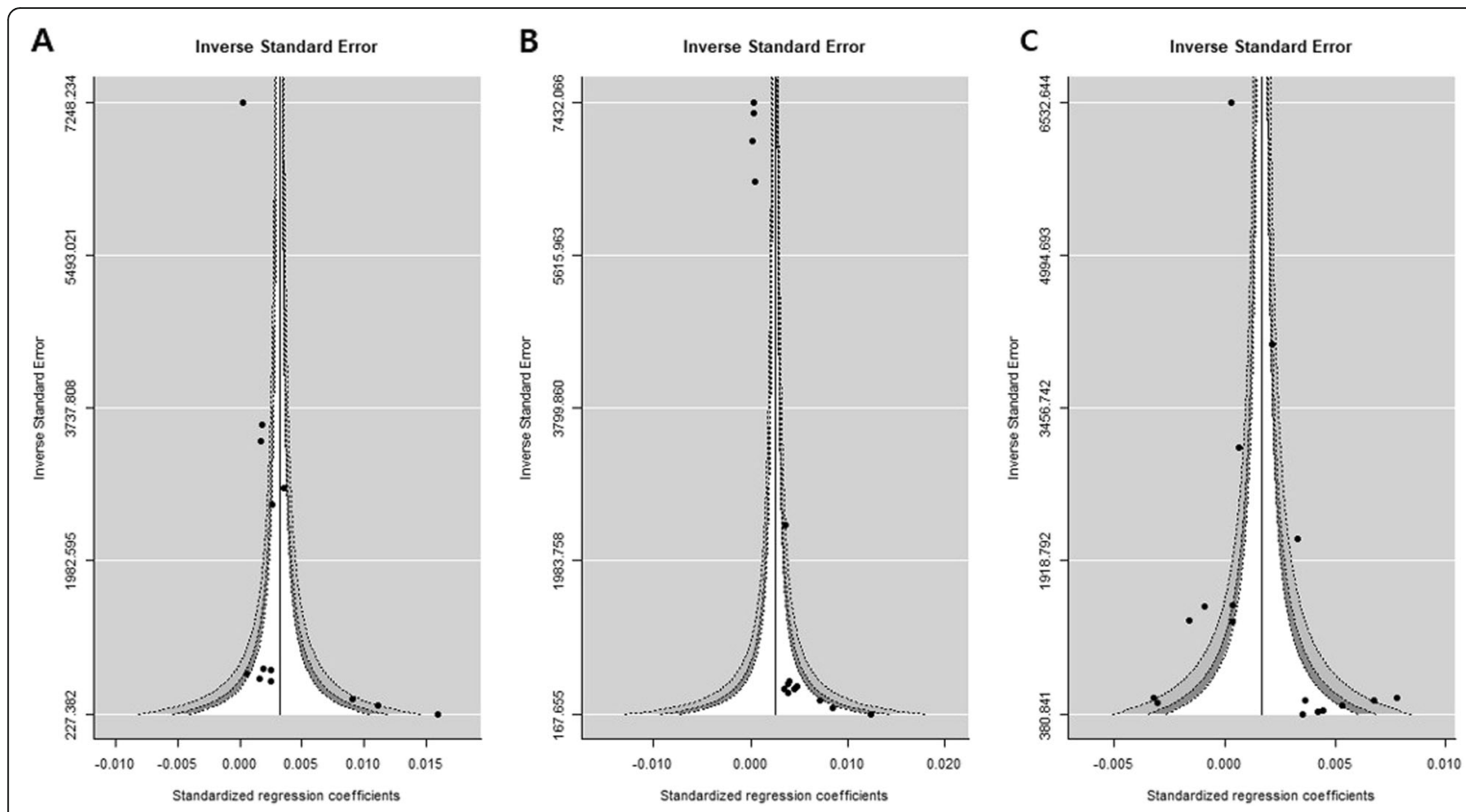

Fig. 7 Funnel plots of term birth weight for publication bias. The analysis was adjusted for demographic characteristics of the subjects (left panel, $P=0.0005$ for Egger's asymmetry test of the funnel plot), with further adjustment for air quality factors (middle panel, $P<0.0001$ for Egger's test) and demographic and civilization factors regardless of air quality effects (right panel, $P=0.0881$ for Egger's test)

significant association based on the pooled standardized regression coefficient.

Numerous reports on greenness, including case studies and epidemiological and observational studies, have reported positive maternal and infant health outcomes. Those studies analyzed the effects of greenness measurements such as the NDVI. We cautiously interpreted our analyses with the restriction of the greenness effect such that it was measured by NDVI derived from the Landsat Enhanced Thematic Mapper Plus data at a resolution of 30 by $30 \mathrm{~m}$. Therefore, we excluded several studies, including those that measured NDVI using Google Maps or Scotland's Greenspace Map [26, 40-43]; those that adjusted for the effects of water-related variables to estimate the NDVI effect [44]; those with NDVI based on land surface reflectance of visible (red) and near-infrared wavelengths [45]; and those with NDVI and surface radiation temperature, which tended to have the lowest surface water values [46].

In this meta-analysis, the investigation of the association between greenness and pregnancy outcomes might assume that exposure to greenness would result in reduced stress and related distress, increased physical activity, and enhanced social participation [5, 6, 8, 47]. While weight gain during pregnancy is a normal process and related to a 50 to $70 \%$ decrease in insulin sensitivity compared to that in non-pregnant women, excessive weight gain is related to adverse maternal and neonatal outcomes [48-50]
The few studies that investigated the health benefits of exercise for pregnant women reported no adverse pregnancy outcomes and a change in pregnant life toward a healthier and more active lifestyle [51]. Greenness has been associated with increased physical activity levels. The findings of our study revealed that increased NDVI was consistently positively correlated with birthweight. Furthermore, the dose-response relationship between NDVI buffer distance and birth outcome was examined in a meta-regression analysis revealed a negative trend but no significant difference. Comparisons of the birthweight results revealed a pooled standardized regression coefficient for the 100-m buffer distance adjusted for demographic characteristics and air quality of 0.001 (95\% CI, 0.0004, 0.0016). This value did not differ from that obtained in the former meta-analysis; however, the statistical significance increased as the CI narrowed. If the interpretation of our results remains questionable, some uncertainties can be resolved by examining the findings of the civilizationadjusted effect size (0.0026, 95\% CI: $0.0001,0.0050$ for the $100-\mathrm{m}$ buffer distance) or larger buffer distance $(0.0046$ and 0.0047 for 250 - and 500-m buffer distances, respectively).

Assessed according to NDVI buffer distance, the frequency of LBW, VLBW, or SGA was associated with low NDVI for all buffer sizes, although there were no significant relationships between NDVI buffer distance and poor fetal weight gain. 


\begin{tabular}{|c|c|c|c|c|c|c|c|c|c|}
\hline Author & Year & Air quality & & & & & \multicolumn{2}{|c|}{$\begin{array}{c}\text { Standardized } \\
\text { regression coefficient } \\
(95 \% \mathrm{Cl}) \\
\end{array}$} & \multirow[t]{2}{*}{$\begin{array}{c}\text { Weight with } \\
\text { random-effect } \\
\text { model }\end{array}$} \\
\hline \multicolumn{9}{|c|}{$100 \mathrm{~m}$ buffer size } & \\
\hline Dadvand & 2012 & $\mathrm{NO}_{2}$ & & & & $\longrightarrow$ & 0.0071 & $(0.0011,0.0132)$ & $1.0 \%$ \\
\hline Hystad & 2014 & $\mathrm{NO}, \mathrm{NO}_{2}, \mathrm{PM}_{25}, \mathrm{BC}$ & & & & 量 & 0.0036 & $(0.0028,0.0044)$ & $14.0 \%$ \\
\hline Laurent & 2013 & $\mathrm{NO}_{\mathrm{x}}$ & & & + & & 0.0001 & $(-0.0002,0.0004)$ & $17.9 \%$ \\
\hline Laurent & 2013 & $\mathrm{PM}_{10}$ & & & + & & 0.0003 & $(0.0001,0.0006)$ & $18.0 \%$ \\
\hline Laurent & 2013 & $\mathrm{PM}_{25}$ & & & + & & 0.0003 & $(0.0000,0.0006)$ & $18.0 \%$ \\
\hline Laurent & 2013 & Local traffic-generated $\mathrm{NO}_{\mathrm{x}}$ & & & 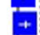 & & 0.0004 & $(0.0001,0.0007)$ & $17.8 \%$ \\
\hline Markevych & 2014 & $\mathrm{NO}_{2}$ & & & & & 0.0038 & $(-0.0009,0.0085)$ & $1.6 \%$ \\
\hline Markevych & 2014 & $\mathrm{PM}_{25}$ & & & - & & 0.0035 & $(-0.0007,0.0077)$ & $1.9 \%$ \\
\hline Subtotal & & & & & - & & 0.0010 & $(0.0004,0.0016)$ & $90.2 \%$ \\
\hline \multicolumn{10}{|c|}{$\begin{array}{l}\text { Heterogeneity: } \text { Tau }^{2}=<0.0001 ; \text { Chi }^{2}=73.53, d f=7(p<0.01) ; l^{2}=90 \% \\
\text { Test for effect in subgroup: } z=3.24(p<0.01)\end{array}$} \\
\hline \multicolumn{10}{|c|}{$250 \mathrm{~m}$ buffer size } \\
\hline Dadvand & 2012 & $\mathrm{NO}_{2}$ & & & 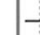 & $\leftrightarrow$ & 0.0085 & $(0.0004,0.0165)$ & $0.6 \%$ \\
\hline Markevych & 2014 & $\mathrm{NO}_{2}$ & & & _ & . & 0.0046 & $(0.0003,0.0088)$ & $1.9 \%$ \\
\hline Markevych & 2014 & $\mathrm{PM}_{25}$ & & & & 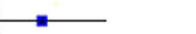 & 0.0039 & $(0.0002,0.0076)$ & $2.4 \%$ \\
\hline Subtotal & & & & & & - & 0.0046 & $(0.0020,0.0073)$ & $4.8 \%$ \\
\hline \multirow{2}{*}{\multicolumn{10}{|c|}{$\begin{array}{l}\text { Heterogeneity: } \text { Tau }^{2}=0 ; \mathrm{Chi}^{2}=1.03, \mathrm{df}=3(p=0.60) ; i^{2}=0 \% \\
\text { Test for effect in subgroup: } z=3.45(p<0.01)\end{array}$}} \\
\hline & & & & & & & & & \\
\hline \multicolumn{10}{|c|}{$500 \mathrm{~m}$ buffer size } \\
\hline Dadvand & 2012 & $\mathrm{NO}_{2}$ & & & & & 0.0124 & $(0.0007,0.0240)$ & $0.3 \%$ \\
\hline Markevych & 2014 & $\mathrm{NO}_{2}$ & & & & 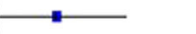 & 0.0048 & $(0.0008,0.0088)$ & $2.1 \%$ \\
\hline Markevych & 2014 & $\mathrm{PM}_{25}$ & & & & 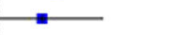 & 0.0039 & $(0.0004,0.0074)$ & $2.6 \%$ \\
\hline Subtotal & & & & & & - & 0.0047 & $(0.0021,0.0073)$ & $4.9 \%$ \\
\hline \multirow{2}{*}{\multicolumn{10}{|c|}{$\begin{array}{l}\text { Heterogeneity: } \text { Tau }^{2}=0 ; \text { Chi }^{2}=1.84, d f=3(p=0.40) ; i^{2}=0 \% \\
\text { Test for effect in subgroup: } z=3.56(p<0.01)\end{array}$}} \\
\hline & & & & & & & & & \\
\hline Overall & & & & & 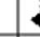 & 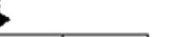 & \multirow[t]{3}{*}{0.0014} & \multirow[t]{3}{*}{$(0.0008,0.0020)$} & \multirow[t]{3}{*}{$100.0 \%$} \\
\hline \multicolumn{3}{|c|}{ Heterogeneity: $\operatorname{Tau}^{2}=<0.0001 ; \mathrm{Chi}^{2}=95.94, d f=13(p<0.01) ; I^{2}=86 \%$} & 厂 & 1 & & 1 & & & \\
\hline \multicolumn{3}{|c|}{ Test for overall effect: $Z=4.41 \quad(p<0.01)$} & -0.01 & -0.005 & 0 & 0.005 & & & \\
\hline
\end{tabular}

The environmental factors were challenging to measure or quantify; therefore, this study attempted to include adjusted summary measures of each study with standardized principles, investigating each demographic characteristic separately, including air quality and civilization. Moreover, considering air quality, adjustment for the concentrations of fine PM was analyzed separately to precisely identify the effects of this confounder (Supplementary Figure S2). The overall standardized regression coefficient was 0.0003 (95\% CI: $0.0002,0.0005)$, which showed the same direction but a smaller coefficient than that for the adjustment for overall air quality. Because the concentration of the PM itself has an adverse effect on birthweight $[52,53]$, it is important to adjust for this factor and provide a careful interpretation. Interestingly, increased greenness showed decreased PTD or VPTD despite poor air quality and civil environment (population density, traffic density,

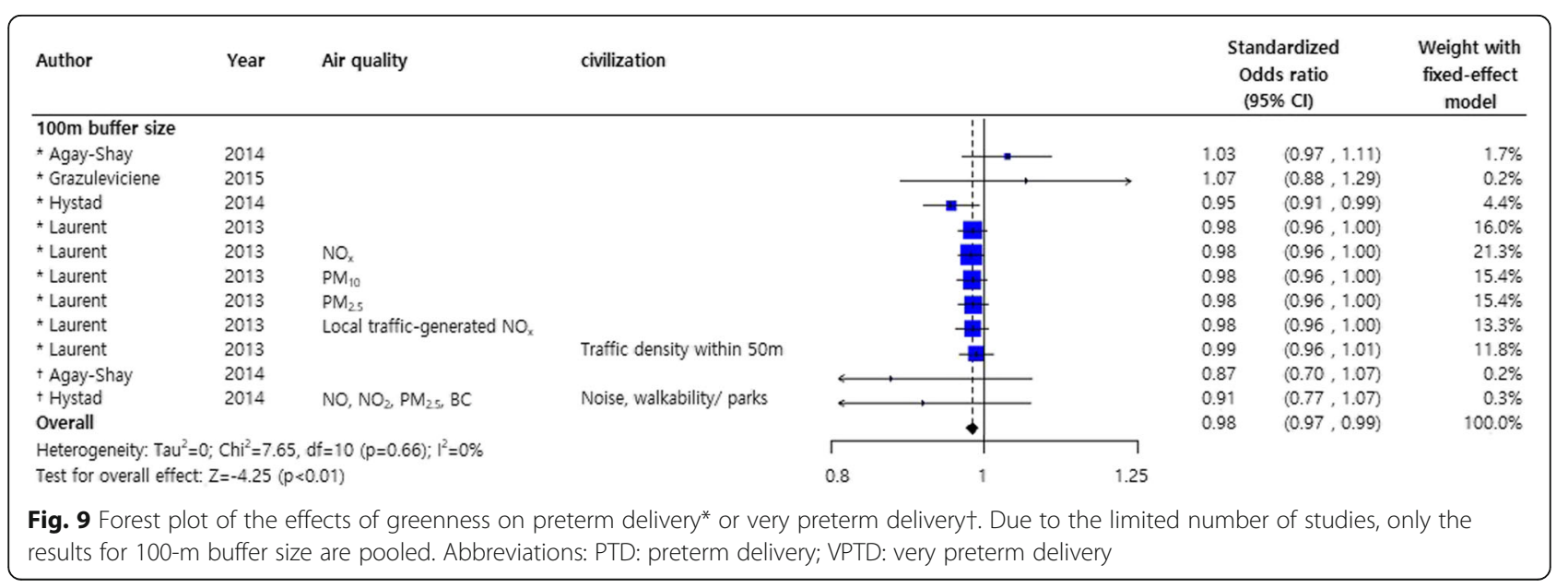


and noise, among others) Therefore, further research for the public health community regarding residential greenness related to environmental medicine and public health is needed to investigate the associations among residential greenness, air pollution, fetal development, and pregnancy outcomes.

Indeed, living in a green space is associated with positive impacts on the health and well-being of pregnant women. In Korea, a forest therapy called "Sup-TaeGyo" was specifically developed as a prenatal education program and provided some evidence for the physical and psychological benefits of exposure to greenness, including its impact on prenatal health and birth outcomes (Supplementary Table S2). Various antenatal programs are traditionally offered to support the mental and physical health of pregnant women over the whole pregnancy period to ensure a healthy birth. Lifestyle interventions with education or instruction on behaviors such as eating habits and physical activity during pregnancy have been emphasized to help prevent adverse pregnancy outcomes [54, 55]. Most of the reports were case studies written in the Korean language that evaluated mental health outcomes, mainly depression and emotional status, but which did not report physical health outcomes.

This study may be challenging to assemble an evidence base for the effect of greenness and associated air pollution on the birth outcomes; thus, more research is needed to validate and evaluate the health outcomes and to identify underlying mechanisms. Although air pollution and civilization were considered potential mediators in this study, other factors, such as physical activity and social interaction, may also affect the health outcomes. In the future, robust randomized clinical trials should be conducted to evaluate the effect of the greenness environment related to air pollution and civilization on diverse maternal health and birth outcomes. Systematic reviews and meta-analyses are needed to investigate the relationship between residential environments with various greenery and pregnancy outcomes with the categorization of maternal and fetal health to aid in the development of future guidelines for green space life.

This study provides evidence that a positive association between greenness and pregnancy outcomes has certain limits on the diversity of the interventions used. The greenness measurement methodologies associated with pregnancy outcomes has made some difficulties in the selection of eligible studies and might remain a barrier to further research. As a method of greenness measurement, the NDVI is not adequate for determining the types of plants and their uses, such as a private garden or public park.

An observational study included in this analysis focused on the effects of greenness during pregnancy and reported another limitation that the greenness properties do not affect the viability in the outcome process. Tracking the results from the time of conception or prior to conception will aid in addressing this limitation.

Table 1 shows the nearly 10 -year gap between the dates of publication of previous studies and the present study. While no publication bias was observed, the research findings (pregnancy outcomes) should be interpreted cautiously in consideration of the development of medical technology, changes in the greenness of the environments, and development of urban civilizations in this time period.

\section{Conclusions}

The results of this review suggest that the greenness of the environment has a positive effect on pregnancy outcomes including decreased LBW, SGA, or preterm birth, despite poor air quality and civilization. However, some of the studies included in the meta-analyses had poor study quality and high heterogeneity; thus, researchers should investigate further with caution. In this context, in the era of low fertility and aging, emphasis should be placed on increasing the social agreement for including green spaces in cities, the importance of green space management and planning in terms of environmental medicine, and public health.

\section{Supplementary information}

Supplementary information accompanies this paper at https://doi.org/10. 1186/s12940-020-00649-z.

Additional file 1 : Supplementary Figure S1. Sensitivity analysis of the effects of greenness on term birth weight adjusted for subject demographic characteristics only by omitting the most influential study result, as described by Dadvand et al. (2012c) [16]

Additional file $\mathbf{2}$ : Supplementary Figure S2. Sensitivity analysis of the effects of greenness on term birth weight, adjusted for subject demographics and $\mathrm{PM}_{\times}$as a measure of air pollution

Additional file $\mathbf{3}$ : Supplementary Figure S3. A random-effects metaregression analysis of buffer sizes on the standardized regression coefficient for birth weight $(A)$ and on the standardized logarithm of low birthweight (LBW, VLBW, or SGA) per 0.1 NDVI meter increases (B), both adjusted for subject demographic variables and civilization factors. Abbreviations: LBW: low birth weight; VLBW: very low birth weight; SGA: small for gestational age; NDVI: normalized difference vegetation index

Additional file 4 : Supplementary Table S1. Search terms used for the review. Supplementary Table S2. Studies on antenatal education in green space in Korea that investigated "Sup-TaeGyo".

\section{Abbreviations}

NDVI: Normalized difference vegetation index; ETM +: Enhanced Thematic Mapper Plus; LBW: Low birth weight; VLBW: Very low birth weight; SGA: Small for gestational age; PTD: Preterm delivery; VPTD: Very preterm delivery; OR: Odds Ratio; SD: Standard deviation; Cl: Confidence interval; IQR: Interquartile range; PM: Particular matter; RoBANS: Risk of Bias Assessment tool for Non-randomized Study 


\section{Authors' contributions}

$\mathrm{KJL}, \mathrm{HM}$, and $\mathrm{JL}$ contributed to the conception and design of the study. KLL, HM, HRY, ELP, ARP, and JL researched the strategies and performed database searches for related articles. KL, HM, HRY, ELP, and ARP contributed to the literature review. KLL, HM, HRY, ELP, and ARP conducted data extraction and quality assessment. $\mathrm{KL}, \mathrm{HM}$, and $\mathrm{JL}$ contributed to the interpretation of the results. $J \mathrm{~L}$ and $\mathrm{HC}$ commented on the protocol and guided for the searches. $\mathrm{KL}$ and $\mathrm{JL}$ confirmed quality assessments and checked the analyzed data. $\mathrm{KL}$ and $\mathrm{HM}$ wrote the first draft of the paper. KL finalized the paper with input from HRY, ELP, ARP, HC, and KH. All authors contributed to the interpretation of data and reviewed and approved the final version of the manuscript. KL and $J L$ had full access to all of the data in the study and had final responsibility for the decision to submit for publication.

\section{Funding}

None.

\section{Availability of data and materials}

The datasets generated and analyzed during the current study are not publicly available due to lack of permission but are available from the corresponding author on reasonable request.

\section{Ethics approval and consent to participate}

Not applicable.

\section{Consent for publication}

Not applicable.

\section{Competing interests}

The authors declare that they have no competing interests.

\section{Author details}

${ }^{1}$ Department of Obstetrics and Gynecology, Korea University Medicine, 73, Goryeodae-ro, Seongbuk-gu, Seoul 02841, South Korea. ${ }^{2}$ Department of Preventive Medicine, Korea University College of Medicine, Seoul, South Korea. ${ }^{3}$ Department of Public Health, Korea University Graduate School, 73, Goryeodae-ro, Seongbuk-gu, Seoul 02841, South Korea. ${ }^{4}$ Department of Biostatistics, Korea University College of Medicine, 73, Goryeodae-ro, Seongbuk-gu, Seoul, South Korea. ${ }^{5}$ Graduate School of Integrative Medicine, Cha University, Pocheon-si, Gyeonggi-do, South Korea.

Received: 19 May 2020 Accepted: 21 August 2020

Published online: 27 August 2020

\section{References}

1. Dzhambov AM, Dimitrova DD, Dimitrakova ED. Association between residential greenness and birth weight: systematic review and meta-analysis. Urban For Urban Green. 2014;13:621-9.

2. McCormack GR, Rock M, Toohey AM, Hignell D. Characteristics of urban parks associated with park use and physical activity: a review of qualitative research. Health Place. 2010;16:712-26.

3. Collaborators GBDRF. Global, regional, and national comparative risk assessment of 84 behavioural, environmental and occupational, and metabolic risks or clusters of risks for 195 countries and territories, 19902017: a systematic analysis for the global burden of disease study 2017. Lancet. 2018;392:1923-94.

4. (WHO) WHO. Global Health Observatory $(\mathrm{GHO})$ data 2019. Available from: https://www.who.int/gho/urban_health/situation_trends/urban_population_ growth_text/en/2019.

5. Bedimo-Rung AL, Mowen AJ, Cohen DA. The significance of parks to physical activity and public health: a conceptual model. Am J Prev Med. 2005;28:159-68

6. James P, Banay RF, Hart JE, Laden F. A review of the health benefits of greenness. Curr Epidemiol Rep. 2015;2:131-42.

7. Frumkin H, Bratman GN, Breslow SJ, Cochran B, Kahn PH Jr, Lawler JJ, et al. Nature contact and human health: a research agenda. Environ Health Perspect. 2017:125:075001.

8. Fong KC, Hart JE, James P. A review of epidemiologic studies on greenness and health: updated literature through 2017. Curr Environ Health Rep. 2018; 5:77-87.
9. Hansen MM, Jones R, Tocchini K. Shinrin-Yoku (Forest bathing) and nature therapy: a state-of-the-art review. Int J Environ Res Public Health. 2017;14: 851.

10. Markevych I, Schoierer J, Hartig T, Chudnovsky A, Hystad P, Dzhambov AM, et al. Exploring pathways linking greenspace to health: Theoretical and methodological guidance; 2017. p. 301-17.

11. Barker DJ, Gelow J, Thornburg K, Osmond C, Kajantie E, Eriksson JG. The early origins of chronic heart failure: impaired placental growth and initiation of insulin resistance in childhood. Eur J Heart Fail. 2010;12:819-25.

12. Dadvand P, de Nazelle A, Figueras F, Basagaña X, Su J, Amoly E, et al. Green space, health inequality and pregnancy. Environ Int. 2012;40:110-5.

13. Sram RJ, Binkova B, Dejmek J, Bobak M. Ambient air pollution and pregnancy outcomes: a review of the literature. Environ Health Perspect. 2005;113:375-82.

14. Vrijheid M, Martinez D, Manzanares S, Dadvand P, Schembari A, Rankin J, et al. Ambient air pollution and risk of congenital anomalies: a systematic review and meta-analysis. Environ Health Perspect. 2011:119:598-606.

15. Dadvand P, de Nazelle A, Triguero-Mas M, Schembari A, Cirach M, Amoly E, et al. Surrounding greenness and exposure to air pollution during pregnancy: an analysis of personal monitoring data. Environ Health Perspect. 2012;120:1286-90.

16. Hegaard HK, Pedersen BK, Nielsen BB, Damm P. Leisure time physical activity during pregnancy and impact on gestational diabetes mellitus, preeclampsia, preterm delivery and birth weight: a review. Acta Obstet Gynecol Scand. 2007;86:1290-6.

17. Poudevigne MS, O'Connor PJ. A review of physical activity patterns in pregnant women and their relationship to psychological health. Sports Med. 2006:36:19-38.

18. Both MI, Overvest MA, Wildhagen MF, Golding J, Wildschut HI. The association of daily physical activity and birth outcome: a population-based cohort study. Eur J Epidemiol. 2010;25:421-9.

19. Huang $\mathrm{H}$, Coleman S, Bridge JA, Yonkers K, Katon W. A meta-analysis of the relationship between antidepressant use in pregnancy and the risk of preterm birth and low birth weight. Gen Hosp Psychiatry. 2014;36:13-8.

20. Agay-Shay K, Peled A, Crespo AV, Peretz C, Amitai Y, Linn S, et al. Green spaces and adverse pregnancy outcomes. Occup Environ Med. 2014;71:562-9.

21. Moher D, Shamseer L, Clarke M, Ghersi D, Liberati A, Petticrew M, et al. Preferred reporting items for systematic review and meta-analysis protocols (PRISMA-P) 2015 statement. Syst Rev. 2015:4:1.

22. Hystad P, Davies HW, Frank L, Van Loon J, Gehring U, Tamburic L, et al. Residential greenness and birth outcomes: evaluating the influence of spatially correlated built-environment factors. Environ Health Perspect. 2014 122:1095-102

23. Sterne JA, Sutton AJ, loannidis JP, Terrin N, Jones DR, Lau J, et al. Recommendations for examining and interpreting funnel plot asymmetry in meta-analyses of randomised controlled trials. Bmj. 2011;343:d4002.

24. Cusack L, Sbihi H, Larkin A, Chow A, Brook JR, Moraes T, et al. Residential green space and pathways to term birth weight in the Canadian Healthy Infant Longitudinal Development (CHILD) Study. 2018.

25. Agay-Shay K, Michael Y, Basagaña X, Martínez-Solanas È, Broday D, Lensky $I M$, et al. Mean and variance of greenness and pregnancy outcomes in Tel Aviv during 2000-14: Iongitudinal and cross-sectional approaches. Int J Epidemiol. 2018;48:1054-72.

26. Ebisu K, Holford TR, Bell ML. Association between greenness, urbanicity, and birth weight. Sci Total Environ. 2016;542(Pt A):750-6.

27. (WHO) WHO. Trends in maternal mortality: 1990 to 2015: estimates by WHO UNICEF, UNFPA, World Bank Group and the United Nations Population Division. WHO Library Cataloguing-in-Publication Data. 2015.

28. Fong KC, Kloog I, Coull BA, Koutrakis P, Laden F, Schwartz JD, et al. Residential greenness and birthweight in the state of Massachusetts, USA nt J Environ Res Public Health. 2018;15:1248.

29. Grazuleviciene R, Danileviciute A, Dedele A, Vencloviene J, Andrusaityte S, Uzdanaviciute I, et al. Surrounding greenness, proximity to city parks and pregnancy outcomes in Kaunas cohort study. Int J Hygiene Environ Health. 2015;218:358-65.

30. Nieminen $P$, Lehtiniemi H, Huusko A, Vahakangas K, Rautio A Polychlorinated biphenyls (PCBs) in relation to secondary sex ratio--a systematic review of published studies. Chemosphere. 2013;91:131-8.

31. Green S, Higgins J. Glossary. Cochrane Handbook for Systematic Reviews of Interventions 4.2. 5 [updated May 2005]; 2009. 
32. Peters JL, Sutton AJ, Jones DR, Abrams KR, Rushton L. Contour-enhanced meta-analysis funnel plots help distinguish publication bias from other causes of asymmetry. J Clin Epidemiol. 2008;61:991-6.

33. Egger M, Davey Smith G, Schneider M, Minder C. Bias in meta-analysis detected by a simple, graphical test. Bmj. 1997;315:629-34.

34. Dadvand P, Sunyer J, Basagaña X, Ballester F, Lertxundi A, FernándezSomoano A, et al. Surrounding greenness and pregnancy outcomes in four Spanish birth cohorts. Environ Health Perspect. 2012;120:1481-7.

35. Laurent $\mathrm{O}, \mathrm{Wu}$ J, Li L, Milesi C. Green spaces and pregnancy outcomes in Southern California. Health Place. 2013;24:190-5.

36. Markevych I, Fuertes E, Tiesler CMT, Birk M, Bauer C-P, Koletzko S, et al. Surrounding greenness and birth weight: results from the GINIplus and LISAplus birth cohorts in Munich. Health Place. 2014;26:39-46.

37. Kim SY, Park JE, Lee YJ, Seo H-J, Sheen S-S, Hahn S, et al. Testing a tool for assessing the risk of bias for nonrandomized studies showed moderate reliability and promising validity. J Clin Epidemiol. 2013;66:408-14.

38. Cusack L, Larkin A, Carozza SE, Hystad P. Associations between multiple green space measures and birth weight across two US cities. Health Place. 2017:47:36-43.

39. Glazer KB, Eliot MN, Danilack VA, Carlson L, Phipps MG, Dadvand P, et al. Residential green space and birth outcomes in a coastal setting. Environ Res. 2018:163:97-107.

40. Young C, Laurent O, Chung J, Wu J. Geographic distribution of healthy resources and adverse pregnancy outcomes. Matern Child Health J. 2016;20: 1673-9.

41. Nichani V, Dirks K, Burns B, Bird A, Morton S, Grant C. Green space and pregnancy outcomes: evidence from growing up in New Zealand. Health Place. 2017:46:21-8.

42. Richardson EA, Shortt NK, Mitchell R, Pearce J. A sibling study of whether maternal exposure to different types of natural space is related to birthweight. Int J Epidemiol. 2018;47:146-55.

43. Donovan GH, Michael YL, Butry DT, Sullivan AD, Chase JM. Urban trees and the risk of poor birth outcomes. Health Place. 2011;17:390-3.

44. Abelt K, McLafferty S. Green streets: urban Green and birth outcomes. Int J Environ Res Public Health. 2017;14:771.

45. Weier J HD. Measuring vegetation (NDVI \& EVI) 2011. Available from: http:// earthobservatory.nasa.gov/Features/MeasuringVegetation/:NASA2011.2011.

46. Kumar DJAP. Remote sensing based vegetation indices analysis to improve water resources management in urban environment. Aquatic Procedia. 2015:4:1374-80.

47. Dzhambov A, Hartig T, Markevych I, Tilov B, Dimitrova D. Urban residential greenspace and mental health in youth: different approaches to testing multiple pathways yield different conclusions. Environ Res. 2018;160:47-59.

48. Margerison Zilko CE, Rehkopf D, Abrams B. Association of maternal gestational weight gain with short- and long-term maternal and child health outcomes. Am J Obstet Gynecol. 2010;202:574.e1-8.

49. Wen T, Lv Y. Inadequate gestational weight gain and adverse pregnancy outcomes among normal weight women in China. Int J Clin Exp Med. 2015; 8:2881-6.

50. Cho EH, Hur J, Lee KJ. Early gestational weight gain rate and adverse pregnancy outcomes in Korean women. PLoS One. 2015;10:e0140376.

51. Barakat R, Perales M. Resistance exercise in pregnancy and outcome. Clin Obstet Gynecol. 2016;59:591-9.

52. Bell ML, Belanger K, Ebisu K, Gent JF, Lee HJ, Koutrakis P, et al. Prenatal exposure to fine particulate matter and birth weight: variations by particulate constituents and sources. Epidemiology. 2010;21:884-91.

53. Bosetti C, Nieuwenhuijsen MJ, Gallus S, Cipriani S, La Vecchia C, Parazzini F. Ambient particulate matter and preterm birth or birth weight: a review of the literature. Arch Toxicol. 2010:84:447-60.

54. Catalano P, deMouzon SH. Maternal obesity and metabolic risk to the offspring: why lifestyle interventions may have not achieved the desired outcomes. Int J Obes (Lond). 2015;39:642-9.

55. Shepherd E, Gomersall JC, Tieu J, Han S, Crowther CA, Middleton P. Combined diet and exercise interventions for preventing gestational diabetes mellitus. Cochrane Database Syst Rev. 2017;11:CD010443.

\section{Publisher's Note}

Springer Nature remains neutral with regard to jurisdictional claims in published maps and institutional affiliations. 